\title{
New hadrosaurid dinosaurs from the uppermost Cretaceous of northeastern China
}

Pascal Godefroit, Hai Shulin, Yu Tingxiang, and Pascaline Lauters

Acta Palaeontologica Polonica 53 (1), 2008: 47-74 doi:http://dx.doi.org/10.4202/app.2008.0103

Several hundred disarticulated dinosaur bones have been recovered from a large quarry at Wulaga (Heilongjiang Province, China), in the Upper Cretaceous (Maastrichtian) Yuliangze Formation. The Wulaga quarry can be regarded as a monodominant bonebed: more than $80 \%$ of the bones belong to a new lambeosaurine hadrosaurid, Sahaliyania elunchunorum gen. et sp. nov. This taxon is characterised by long and slender paroccipital processes, a prominent lateral depression on the dorsal surface of the frontal, a quadratojugal notch that is displaced ventrally on the quadrate, and a prepubic blade that is asymmetrically expanded, with an important emphasis to the dorsal side. Phylogenetic analysis shows that Sahaliyania is a derived lambeosaurine that forms a monophyletic group with the corythosaur and parasauroloph clades. Nevertheless, the exact position of Sahaliyania within this clade cannot be resolved on the basis of the available material. Besides Sahaliyania, other isolated bones display a typical hadrosaurine morphology and are referred to Wulagasaurus dongi gen. et sp. nov., a new taxon characterised by the maxilla pierced by a single foramen below the jugal process, a very slender dentary not pierced by foramina, and by the deltopectoral crest (on the humerus) oriented cranially. Phylogenetic analysis indicates that Wulagasaurus is the most basal hadrosaurine known to date. Phylogeographic data suggests that the hadrosaurines, and thus all hadrosaurids, are of Asian origin, which implies a relatively long ghost lineage of approximately 13 million years for basal hadrosaurines in Asia.

Key words: Dinosauria, Hadrosauridae, Sahaliyania elunchunorum, Wulagasaurus dongi, phylogeny, palaeogeography, Late Cretaceous, China.

Pascal Godefroit pascal.godefroit@naturalsciences.be and Pascaline Lauters plauters@ulb.ac.be

, Department of Palaeontology, Institut royal des Sciences naturelles de Belgique, rue Vautier 29, 1000 Bruxelles, Belgium; Hai Shulin haishulin@126.com and Yu Tingxiang, Geological Museum of Heilongjiang, Xiangfang District, Harbin, China. 
This is an open-access article distributed under the terms of the Creative Commons

Attribution License (for details please see creativecommons.org), which permits unrestricted use, distribution, and reproduction in any medium, provided the original author and source are credited.

FoF Full text $(1,295.6 \mathrm{kB})$ 